\title{
Nonlinear Finite Strain Consolidation Analysis with Secondary Consolidation Behavior
}

\author{
Jieqing Huang, ${ }^{1,2,3}$ Xinyu Xie, ${ }^{1,2,3}$ Jifa Zhang, ${ }^{4}$ Jinzhu Li, ${ }^{2}$ and Wenjun Wang ${ }^{2}$ \\ ${ }^{1}$ Research Center of Coastal and Urban Geotechnical Engineering, Zhejiang University, Hangzhou 310058, China \\ ${ }^{2}$ School of Civil Engineering \& Architecture, Ningbo Institute of Technology, Zhejiang University, Ningbo 315100, China \\ ${ }^{3}$ MOE Key Laboratory of Soft Soils and Geoenvironmental Engineering, Zhejiang University, Hangzhou 310058, China \\ ${ }^{4}$ School of Aeronautics and Astronautics, Zhejiang University, Hangzhou 310027, China \\ Correspondence should be addressed to Xinyu Xie; xiexinyu@zju.edu.cn
}

Received 8 January 2014; Accepted 25 March 2014; Published 17 April 2014

Academic Editor: Gianluca Ranzi

Copyright (c) 2014 Jieqing Huang et al. This is an open access article distributed under the Creative Commons Attribution License, which permits unrestricted use, distribution, and reproduction in any medium, provided the original work is properly cited.

\begin{abstract}
This paper aims to analyze nonlinear finite strain consolidation with secondary consolidation behavior. On the basis of some assumptions about the secondary consolidation behavior, the continuity equation of pore water in Gibson's consolidation theory is modified. Taking the nonlinear compressibility and nonlinear permeability of soils into consideration, the governing equation for finite strain consolidation analysis is derived. Based on the experimental data of Hangzhou soft clay samples, the new governing equation is solved with the finite element method. Afterwards, the calculation results of this new method and other two methods are compared. It can be found that Gibson's method may underestimate the excess pore water pressure during primary consolidation. The new method which takes the secondary consolidation behavior, the nonlinear compressibility, and nonlinear permeability of soils into consideration can precisely estimate the settlement rate and the final settlement of Hangzhou soft clay sample.
\end{abstract}

\section{Introduction}

The secondary consolidation has been studied for decades. It is considered that the rheological behavior accounts for the secondary consolidation. Nevertheless, the controversy regarding whether or not the rheological behavior exists in primary consolidation continues today. According to the summarization of Ladd et al. [1] and Jamiolkowski et al. [2], there are two hypotheses: Hypothesis A and Hypothesis B. Hypothesis A considers that the rheological behavior appears after primary consolidation. However, Hypothesis B considers that the rheological behavior occurs while primary consolidation begins. Mesri, a famous scholar who supported Hypothesis A, did long-term researches on the compression index $C_{c}$ and the secondary compression index $C_{\alpha}$ [3-5]. He found that the values of $C_{\alpha} / C_{c}$ are almost constant for a majority of inorganic soft clays and the highly organic plastic clays. The scholars who support Hypothesis B think that the way of dividing consolidation into primary consolidation and secondary consolidation is highly subjective. Barden thought that the rheological behavior should not be neglected during primary consolidation [6]. Wahls considered that the settlement of soils includes the time-dependent deformation in primary consolidation [7]. Aboshi, Leroueil et al. and Kabbaj et al. also documented that the rheological behavior exists in primary consolidation [8-11]. Because the rheological behavior causes the secondary consolidation, we call it the secondary consolidation behavior in the following sections of this paper.

Gibson et al. derived the one-dimensional (1D) finite strain consolidation equation which was called the Gibson equation [12]. They considered the weight of soils and took void ratio as the control variable in the derivation. In the research fields of sedimentation and consolidation, the Gibson equation was widely used [13-15]. Many scholars carried in-depth researches on finite strain consolidation [16-18]. However, the secondary consolidation behavior is not considered in the majority of existing finite strain consolidation theories. Many experimental and in situ data indicate that the settlement of soils still increases after primary consolidation, that is, under the condition of almost constant effective stress $[19,20]$. Dan summarized the experimental results 
for some Chinese soft clays [19]. It is found that Shenzhen clay, Tianjin clay, Zhengzhou clay, Ningbo clay, and Wenzhou clay all show the secondary consolidation behavior clearly. So it is necessary to consider the secondary consolidation behavior in the study of finite strain consolidation. Ding et al. presented a coupling model for 1D finite strain primarysecondary consolidation [21]. Nevertheless, they did not perform calculation or analysis to verify the rationality of the model.

The objective of this paper is to analyze nonlinear finite strain consolidation with secondary consolidation behavior. Based on some assumptions about the secondary consolidation behavior, the continuity equation of pore water in Gibson's consolidation theory is modified. Taking the nonlinear compressibility and nonlinear permeability of soils into consideration, the new governing equation for numerical analysis can be derived. In order to obtain the calculation parameters for numerical analysis, lab tests of Hangzhou soft clay samples are carried out. Then the finite element method is chosen to solve the new governing equation and the calculation results of excess pore water pressure and settlement are analyzed. Afterwards, the calculation results of this new method and other two methods are compared in order to find the best method. Finally, numerical analysis is performed to study the sensitivity of the new secondary compression index.

\section{Mathematical Modeling}

According to the existing studies [6-11], we consider that the secondary consolidation behavior should be considered in the whole process of consolidation. As we all know, the conventional secondary compression index $C_{\alpha}$ exists only in secondary consolidation. Thus, a new parameter should be defined to describe the secondary consolidation behavior. We name it the new secondary compression index and use a new symbol $C_{s}$ to represent it. It should be pointed out that $C_{s}$ can be calculated with the classical method of calculating $C_{\alpha}$ but it exists in both primary consolidation and secondary consolidation. In order to introduce a nonlinear finite strain consolidation theory with secondary consolidation behavior, the following three assumptions are made.

(1) The secondary consolidation behavior exists in both primary consolidation and secondary consolidation.

(2) The new secondary compression indices $C_{s}$ at different depths of soils are the same.

(3) The new secondary compression index $C_{s}$ remains constant during consolidation.

Gibson et al. derived the governing equation of 1D finite strain consolidation by treating void ratio as the control variable [12]. The Gibson equation is written as follows:

$$
\begin{aligned}
\pm\left(G_{s}\right. & -1) \frac{d}{d e}\left(\frac{k}{1+e}\right) \frac{\partial e}{\partial z}+\frac{\partial}{\partial z}\left[\frac{k}{\gamma_{w}(1+e)} \frac{d \sigma^{\prime}}{d e} \frac{\partial e}{\partial z}\right] \\
+\frac{\partial e}{\partial t} & =0
\end{aligned}
$$

where $z$ is the $1 \mathrm{D}$ space variable in reduced coordinates; $t$ is the time variable; $G_{s}=\gamma_{s} / \gamma_{w}$ is the specific weight of soil particles; $\gamma_{s}$ and $\gamma_{w}$ are the unit weights of soil particles and pore water, respectively; $k$ is the permeability coefficient; $\sigma^{\prime}$ is the effective stress; $e$ is the void ratio. \pm represents that the positive direction of the coordinate is opposite to the direction of gravity or the same.

In their derivation, the following four main equations were applied: (1) the equilibrium equation of soils; (2) the continuity equation of pore water; (3) Darcy's law; (4) the effective stress principle. Here, we modify the continuity equation of pore water. We consider that the whole deformation of soils is equal to the deformation caused by the primary consolidation behavior plus the deformation caused by the secondary consolidation behavior. Hence, the following equation can be obtained:

$$
-\frac{d V}{d t}=\frac{d Q}{d t}-\frac{d V_{s}}{d t},
$$

where $V$ is the whole volume of soils; $Q$ is the volume of expelled water; $V_{s}$ is the volume of soils affected by the secondary consolidation behavior.

Consider the following:

$$
\begin{gathered}
d V=\frac{V}{1+e} d e \\
d Q=\frac{d v}{d \xi} d x d y d \xi d t \\
d V_{s}=\frac{V}{1+e} d e_{s}
\end{gathered}
$$

where $x, y$, and $\xi$ are the three space variables in Eulerian coordinates; the positive direction of the $\xi$ axis is downward; $v=v_{w}-v_{s}$ is the relative velocity of pore water and soil particles; $v_{w}$ and $v_{s}$ are the velocities of pore water and soil particles, respectively; $e$ is the void ratio; $e_{s}$ is the void ratio affected by the secondary consolidation behavior; $e_{s}$ is a portion of $e$.

According to (5), we can obtain

$$
-\frac{d V_{s}}{d t}=-\frac{V}{1+e} \frac{d e_{s}}{d t}=-\frac{V}{1+e} \frac{d e_{s}}{d \log t} \frac{d \log t}{d t} .
$$

After primary consolidation, the deformation of soils is simply caused by the secondary consolidation behavior. When primary consolidation ceases, $e$ reduces to $e_{s}$.

According to the definition of the new secondary compression index, we can obtain

$$
C_{s}=-\frac{d e_{s}}{d \log t} .
$$

Substituting (7) into (6) yields

$$
-\frac{d V_{s}}{d t}=C_{s} \frac{V}{1+e} \frac{1}{t \ln 10} .
$$

Substituting (4) and (8) into (2) yields

$$
-\frac{1}{1+e} \frac{\partial e}{\partial t}=\frac{\partial v}{\partial \xi}+\frac{C_{s}}{1+e} \frac{1}{t \ln 10}
$$


The modified Darcy law can be written as [12]

$$
v=v_{w}-v_{s}=-k i=-\frac{k}{\gamma_{w}} \frac{\partial u}{\partial \xi}
$$

where $i$ is the hydraulic gradient; $u$ is the excess pore water pressure.

Substituting (10) into (9) yields

$$
-\frac{1}{1+e} \frac{\partial e}{\partial t}=-\frac{\partial}{\partial \xi}\left(\frac{k}{\gamma_{w}} \frac{\partial u}{\partial \xi}\right)+\frac{C_{s}}{1+e} \frac{1}{t \ln 10} .
$$

The effective stress principle is written as

$$
\sigma^{\prime}=\sigma-u
$$

where $\sigma^{\prime}$ is the effective stress; $\sigma$ is the total stress.

Differentiating (12) yields

$$
\frac{\partial u}{\partial \xi}=\frac{\partial \sigma}{\partial \xi}-\frac{\partial \sigma^{\prime}}{\partial \xi}
$$

As noted, the positive direction of the $\xi$ axis is downward. The equilibrium equation of soils can be obtained as

$$
\frac{\partial \sigma}{\partial \xi}=\frac{\left(G_{s}-1\right) \gamma_{w}}{1+e}
$$

Substituting (14) into (13) yields

$$
\frac{\partial u}{\partial \xi}=\frac{\left(G_{s}-1\right) \gamma_{w}}{1+e}-\frac{d \sigma^{\prime}}{d e} \frac{\partial e}{\partial \xi} .
$$

Substituting (15) into (11), we attain the 1D finite strain consolidation equation with secondary consolidation behavior in Eulerian coordinates:

$$
\begin{gathered}
\left(G_{s}-1\right) \frac{d}{d e}\left(\frac{k}{1+e}\right) \frac{\partial e}{\partial \xi}-\frac{\partial}{\partial \xi}\left(\frac{k}{\gamma_{w}} \frac{d \sigma^{\prime}}{d e} \frac{\partial e}{\partial \xi}\right) \\
=\frac{1}{1+e} \frac{\partial e}{\partial t}+\frac{C_{s}}{1+e} \frac{1}{t \ln 10} .
\end{gathered}
$$

Under 1D condition, the transformation between Eulerian coordinates and Lagrangian coordinates and the transformation between reduced coordinates and Lagrangian coordinates are shown as follows:

$$
\begin{gathered}
\frac{d \xi}{d a}=\frac{1+e}{1+e_{0}} \\
\frac{d z}{d a}=\frac{1}{1+e_{0}}
\end{gathered}
$$

where $a$ is the 1D space variable in Lagrangian coordinates.
According to the above two transformations, the new consolidation equations in Lagrangian coordinates and reduced coordinates can be obtained:

$$
\begin{gathered}
\left(G_{s}-1\right) \frac{d}{d e}\left(\frac{k}{1+e}\right) \frac{\partial e}{\partial a}-\frac{\partial}{\partial a}\left(\frac{k}{\gamma_{w}} \frac{d \sigma^{\prime}}{d e} \frac{\partial e}{\partial a} \frac{1+e_{0}}{1+e}\right) \\
=\frac{1}{1+e_{0}} \frac{\partial e}{\partial t}+\frac{C_{s}}{1+e_{0}} \frac{1}{t \ln 10}, \\
\left(G_{s}-1\right) \frac{d}{d e}\left(\frac{k}{1+e}\right) \frac{\partial e}{\partial z}-\frac{\partial}{\partial z}\left[\frac{k}{\gamma_{w}(1+e)} \frac{d \sigma^{\prime}}{d e} \frac{\partial e}{\partial z}\right] \\
=\frac{\partial e}{\partial t}+\frac{C_{s}}{t \ln 10} .
\end{gathered}
$$

Equation (19) will be used in the next derivation because a calculation example will be analyzed in the reduced coordinates. It is worth mentioning that (19) can be converted into the Gibson equation if $C_{s}$ is equal to 0 .

In order to solve (1), Gibson et al. made the following two assumptions [13]:

$$
\begin{gathered}
g=-\frac{k}{\gamma_{w}(1+e)} \frac{d \sigma^{\prime}}{d e}=\text { constant } \\
\lambda=-\frac{d}{d e}\left(\frac{d e}{d \sigma^{\prime}}\right)=\text { constant }
\end{gathered}
$$

where $g$ and $\lambda$ are the consolidation coefficient and the gravity coefficient, respectively.

Based on the above assumptions, (1) was transformed into (21). Equation (21) was a linear partial differential equation and then it was solved with the finite difference method [13]:

$$
\pm\left(\gamma_{s}-\gamma_{w}\right) g \lambda \frac{\partial e}{\partial z}-g \frac{\partial^{2} e}{\partial z^{2}}+\frac{\partial e}{\partial t}=0 .
$$

Duncan suggested that the variation of consolidation coefficient should be taken into consideration in the predictions of settlement rates of practical engineering [22]. Leroueil suggested that consolidation must be analyzed by considering compressibility and permeability parameters measured separately [23]. Mesri and Rokhsar used the following two equations to express the relationship between void ratio and effective stress and the relationship between void ratio and permeability coefficient, respectively [24]:

$$
\begin{aligned}
& e=e_{0}-C_{c} \lg \left(\frac{\sigma^{\prime}}{\sigma_{0}^{\prime}}\right), \\
& e=e_{0}+C_{k} \lg \left(\frac{k}{k_{0}}\right),
\end{aligned}
$$

where $C_{c}$ is the compression index; $C_{k}$ is the permeability index; $e_{0}$ is the initial void ratio; $\sigma_{0}^{\prime}$ is the initial effective stress; $k_{0}$ is the initial permeability coefficient.

Tavenas et al. considered that (23) can depict the variation of permeability coefficient with void ratio in the majority of practical engineering [25]. Because (22) and (23) are generally accepted, they are employed to reflect the nonlinear 
TABLE 1: Experimental data of Hangzhou soft clay.

\begin{tabular}{lccccccc}
\hline$C_{c}$ & $C_{k}$ & $C_{s}$ & $e_{0}$ & $k_{0} /\left(\mathrm{m} \cdot \mathrm{minute}^{-1}\right)$ & $\gamma_{s} /\left(\mathrm{kN} \cdot \mathrm{m}^{-3}\right)$ & $g /\left(\mathrm{m}^{2} \cdot \mathrm{minut}^{-1}\right)$ & $\lambda / \mathrm{kPa}^{-1}$ \\
\hline 0.2418 & 0.4191 & $7.735 e(-3)$ & 1.18 & $1.419 e(-8)$ & 26.70 & $3.422 e(-7)$ & $2.028 e(-3)$ \\
\hline
\end{tabular}

compressibility and nonlinear permeability for Hangzhou soft clay, respectively.

Substituting (22) and (23) into (19) yields

$$
\begin{aligned}
& \frac{\left(G_{s}-1\right) k_{0}}{(1+e)^{2}}\left[\frac{\ln 10}{C_{k}}(1+e)-1\right] 10^{\left(e-e_{0}\right) / C_{k}} \frac{\partial e}{\partial z} \\
& +\frac{k_{0} \sigma_{0}^{\prime} \ln 10}{\gamma_{w} C_{c}} \frac{\partial}{\partial z}\left[\frac{1}{1+e} 10^{\left(e-e_{0}\right) / C_{k}-\left(e-e_{0}\right) / C_{c}} \frac{\partial e}{\partial z}\right] \\
& -\frac{\partial e}{\partial t}-\frac{C_{s}}{t \ln 10}=0 .
\end{aligned}
$$

Equation (24) is the new governing equation for numerical analysis in this paper. If $C_{s}$ is equal to 0 , (24) can be converted into (25) which still considers the nonlinear compressibility and nonlinear permeability of soils [26]. The finite element software FlexPDE is chosen to solve (24) and (25):

$$
\begin{aligned}
& \frac{\left(G_{s}-1\right) k_{0}}{(1+e)^{2}}\left[\frac{\ln 10}{C_{k}}(1+e)-1\right] 10^{\left(e-e_{0}\right) / C_{k}} \frac{\partial e}{\partial z} \\
& +\frac{k_{0} \sigma_{0}^{\prime} \ln 10}{\gamma_{w} C_{c}} \frac{\partial}{\partial z}\left[\frac{1}{1+e} 10^{\left(e-e_{0}\right) / C_{k}-\left(e-e_{0}\right) / C_{c}} \frac{\partial e}{\partial z}\right] \\
& -\frac{\partial e}{\partial t}=0 .
\end{aligned}
$$

If the void ratio at a certain depth and time is attained, the corresponding effective stress and permeability coefficient can be calculated with (22) and (23), respectively. If the void ratio is calculated, the settlement at the top surface of soils can be calculated with the following equation:

$$
S(t)=\int_{0}^{l}[e(z, 0)-e(z, t)] d z
$$

\section{Calculation Examples and Analysis}

3.1. Problem Description. The nonlinear finite strain consolidation analysis with secondary consolidation behavior is based on the schematic diagram shown in Figure 1. In this figure, $l$ is the total thickness of the clay layer; $q$ is the uniformly distributed load which is instantaneously applied on the top surface of the clay layer. In the numerical analysis, the value of $q$ is $300 \mathrm{kPa}$. The top and bottom surfaces are both pervious. Take the top surface as the datum plane so the positive direction of the $z$ axis is downward. Considering the weight of clays, the distribution of initial effective stress with depth is triangular. Initial void ratio is corresponding to initial effective stress at different depths of the clay layer. Initial excess pore water pressure is constant with depth. Distributions of initial effective stress and initial excess pore water pressure with depth are shown in Figure 1.

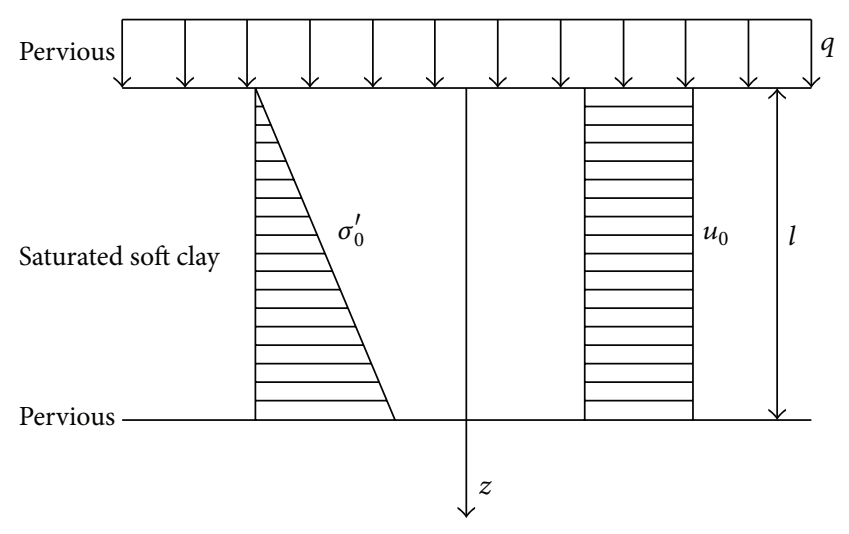

FIGURE 1: Schematic diagram of physical modeling.

The parameters used in the numerical analysis are based on the laboratory tests for Hangzhou soft clay and they are listed in Table 1.

In this section, the following three methods are used to analyze the consolidation behavior of Hangzhou soft clay.

Method 1. The nonlinear finite strain consolidation equation with secondary consolidation behavior, that is, (24), is used.

Method 2. The nonlinear finite strain consolidation equation without secondary consolidation behavior, that is, (25), is used.

Method 3. The Gibson equation with constant consolidation coefficient, that is, (21), is used.

In order to find the best analysis method among the three methods, we will compare the excess pore water pressures calculated with different methods and the time-deformation curves calculated with different methods.

3.2. Calculation Results of Excess Pore Water Pressure. Calculation results of excess pore water pressure are shown in Figure 2. It can be seen from Figure 2(a) that the results calculated with different methods are almost the same at the beginning of primary consolidation ( $t=1$ minute). Because the two surfaces of the clay layer are both pervious, near the surfaces the excess pore water pressures dissipate rapidly. At the meanwhile, in the internal soil the excess pore water pressures do not dissipate. With time elapsing, consolidation develops from the pervious surfaces to the internal soil by degrees. At the time $t=50$ minutes, the excess pore water pressure calculated with Method 1 is the smallest, while the excess pore water pressure calculated with Method 3 is the largest. The calculation result of Method 2 is between the calculation results of the other two methods. At the centerline of the soil, the maximum excess pore water 


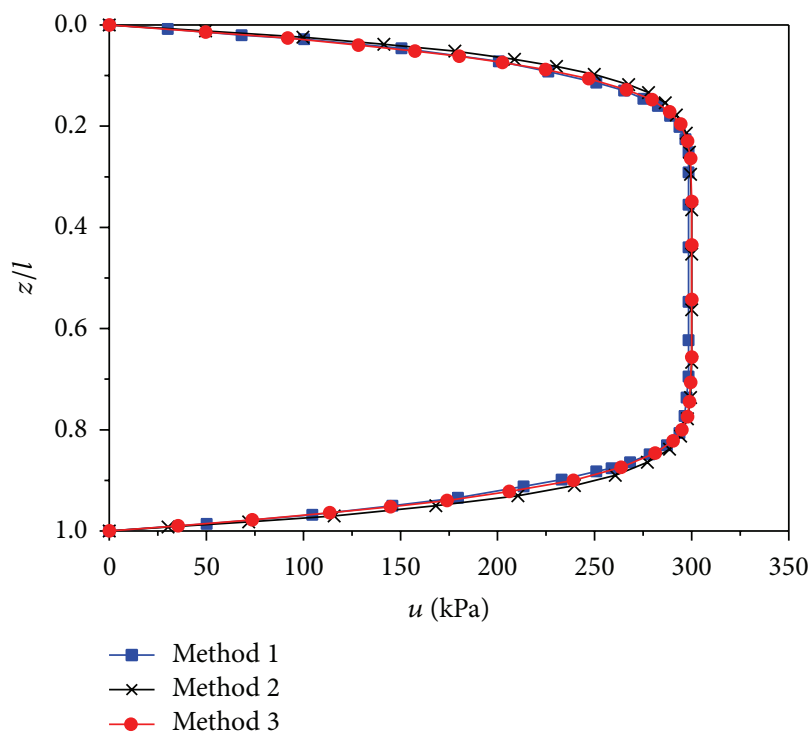

(a) $t=1$ minute

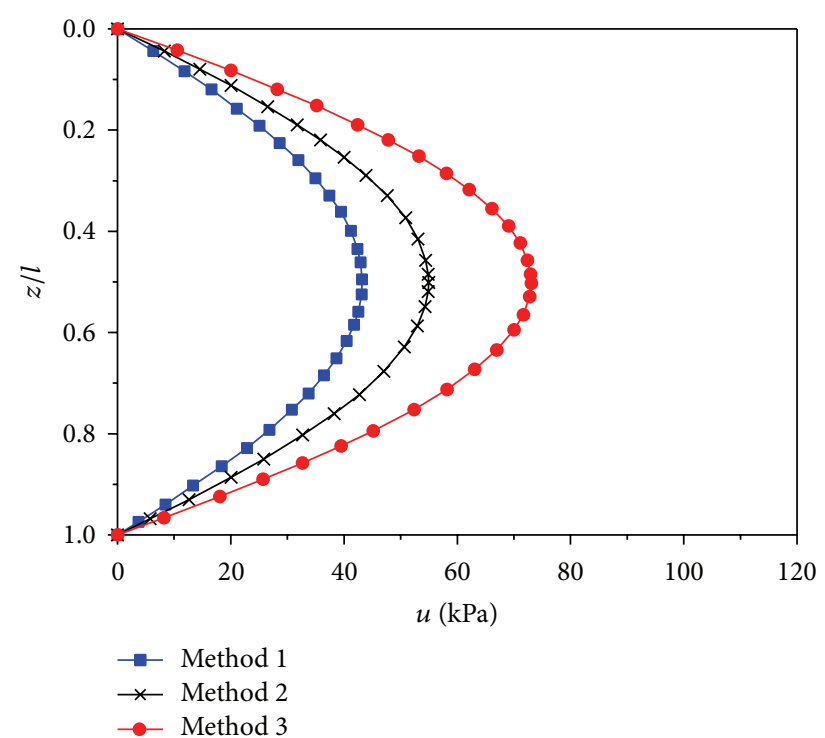

(b) $t=50$ minutes

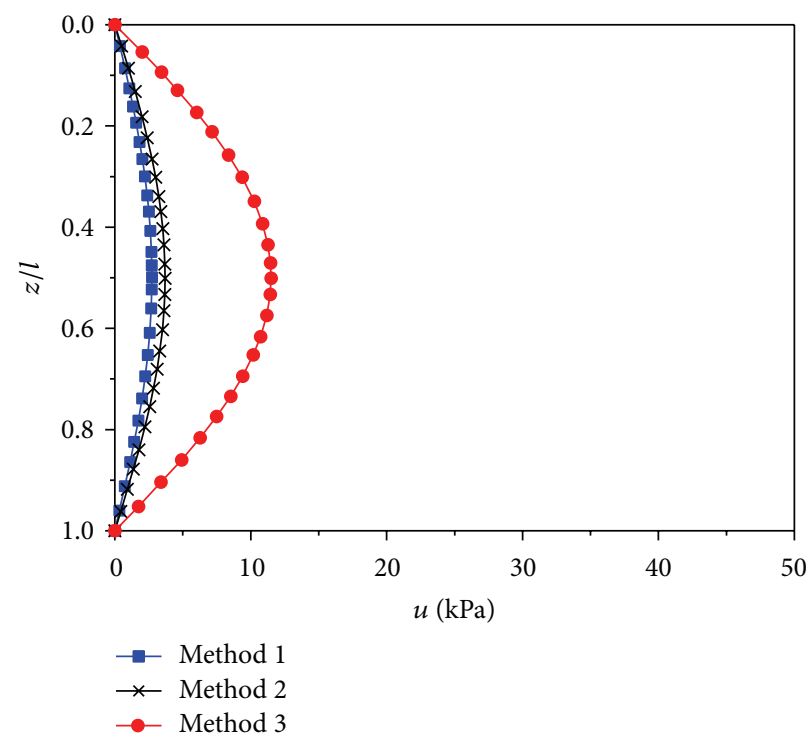

(c) $t=100$ minutes

FIGURE 2: Distributions of excess pore water pressure with normalized depth at three time points.

pressures calculated with Methods 1, 2, and 3 are $43.19 \mathrm{kPa}$, $54.96 \mathrm{kPa}$, and $73.06 \mathrm{kPa}$, respectively. At the time $t=100$ minutes, the excess pore water pressures calculated with Methods 1 and 2 are close to each other and they will reduce to 0 soon. The excess pore water pressure calculated with Method 3 is still the largest and it needs more time to dissipate. At this moment, the maximum excess pore water pressures calculated with Methods 1, 2, and 3 are $2.73 \mathrm{kPa}$, $3.69 \mathrm{kPa}$, and $11.50 \mathrm{kPa}$, respectively.

Compared to Method 3, Method 2 takes the material nonlinearity of soils into consideration. By jointly considering the calculation results of Methods 2 and 3 in Figures 3(a)-3(c), it can be seen that Method 3 may underestimate the excess pore water pressure in the intermediate and final stages of primary consolidation. This implies that it is necessary to consider the nonlinear compressibility and nonlinear permeability of soils. Compared to Method 2, Method 1 considers the secondary consolidation behavior. By jointly considering the calculation results of Methods 1 and 2 in Figures 3(a)3(c), it can be observed that Method 2 may underestimate the excess pore water pressure in the intermediate stage of primary consolidation. So the secondary consolidation behavior should be considered in the study of finite strain consolidation.

3.3. Calculation Results of Settlement. The calculation results and the experimental results of settlement are shown in Figure 3. It can be observed that the settlement calculated 
with Method 3 is smaller than the observed settlement at the beginning of consolidation. Moreover, the final settlement in the test is about $3 \mathrm{~mm}$ while the final settlement calculated with this method is less than $2 \mathrm{~mm}$. This shows that Method 3 underestimates the final settlement. The time-deformation curve calculated with Method 3 becomes a horizontal line after primary consolidation. As mentioned, Method 3 is Gibson's theory which does not include the secondary consolidation. Therefore, the prediction result from this method is unable to capture secondary consolidation behavior after the primary consolidation.

It can be found from Figure 3 that Method 2 also underestimates the settlement at the beginning of consolidation. After about 10 minutes, the calculation result using Method 2 approaches the experimental result gradually. Figure 3 shows that the final settlement calculated with Method 2 is about $2.6 \mathrm{~mm}$. So this method slightly underestimates the final settlement. According to the above calculation and analysis, the calculation result of Method 2 is closer to the experimental result than that of Method 3. Perhaps because the nonlinear compressibility and nonlinear permeability of Hangzhou soft clay are considered in Method 2, this method is more reasonable than Method 3. Ichikawa et al. performed 1D finite strain consolidation analysis under change of permeability [27]. They considered that the secondary consolidation is induced by the nonuniform distribution of permeability. For Method 2, the distribution of permeability with the depth of the clay layer is also nonuniform. Nevertheless, the secondary consolidation behavior cannot be observed in the calculated result. Consequently, we do not agree with Ichikawa's opinion.

It can be observed from Figure 3 that Method 1 can precisely estimate the settlement rate of Hangzhou soft clay sample during consolidation, especially in the initial stage of consolidation. The analysis methods without considering the secondary consolidation behavior, such as Methods 2 and 3 , cannot estimate the settlement rate precisely. So it is necessary to consider the secondary consolidation behavior in the predictions of settlement rates. It can be seen from Figure 3 that the calculation result of Method 1 exhibits the secondary consolidation behavior clearly. Furthermore, the final settlement calculated with Method 1 is very close to the actual final settlement.

Considering five different values of the new secondary consolidation index $C_{s}(0.002,0.004,0.006,0.008$, and 0.010), the time-deformation curves calculated with Method 1 are compared in order to study the sensitivity of $C_{s}$. All parameters used in the numerical analysis are the same as the ones in the aforementioned example except for $C_{s}$. The five time-deformation curves are plotted in Figure 4 . It can be found that $C_{s}$ makes a significant influence on the calculation results of settlement. At each time point, the larger the $C_{s}$, the larger the settlement.

In the initial stage of primary consolidation, $C_{s}$ has a great influence on the calculation results. For example, at the time $t=0.1$ minute, the settlements are approximately $0.21 \mathrm{~mm}, 0.28 \mathrm{~mm}, 0.37 \mathrm{~mm}, 0.54 \mathrm{~mm}$, and $0.79 \mathrm{~mm}$ if $C_{s}$ is $0.002,0.004,0.006,0.008$, and 0.010 , respectively. With time elapsing, the influence of $C_{s}$ decreases gradually. Near

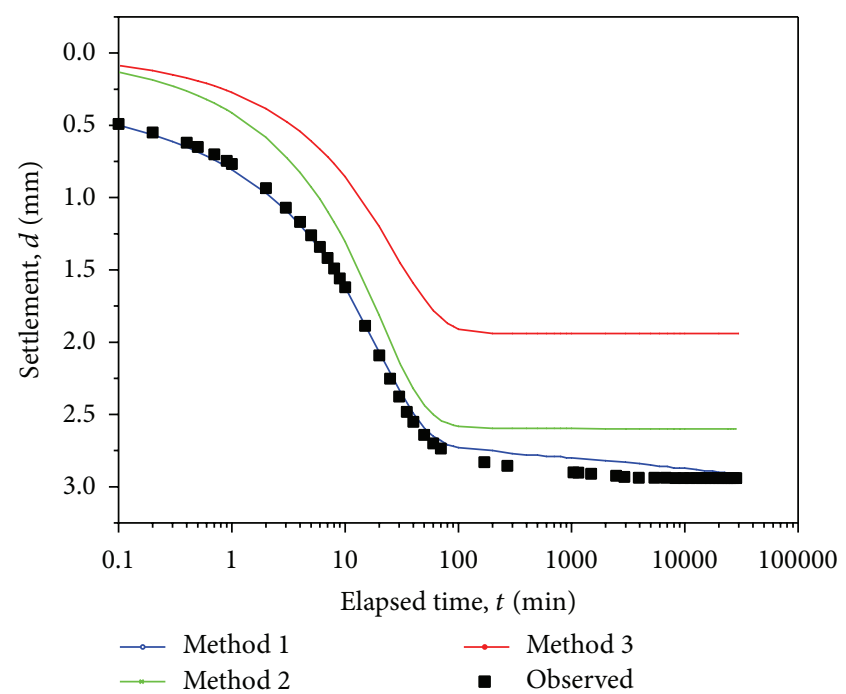

FIGURE 3: Time-deformation curves calculated with different methods.

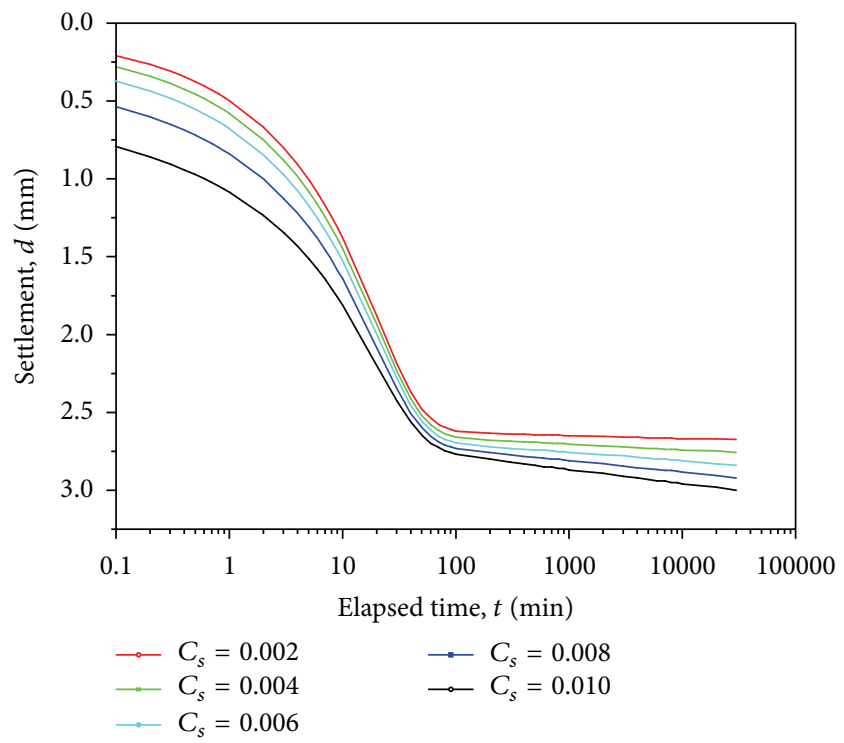

FIGURE 4: Time-deformation curves calculated by considering different new secondary consolidation indices.

the ending time of primary consolidation, the influence of $C_{s}$ is tiny. For instance, at the time $t=50$ minutes, the settlements are approximately $2.48 \mathrm{~mm}, 2.52 \mathrm{~mm}, 2.56 \mathrm{~mm}$, $2.60 \mathrm{~mm}$, and $2.65 \mathrm{~mm}$ if $C_{s}$ is $0.002,0.004,0.006,0.008$, and 0.010 , respectively. It is clear that the ending times of primary consolidation are almost the same under different conditions. In the initial stage of secondary consolidation, the effect of $C_{s}$ is small. With increasing time, the effect of $C_{s}$ increases by degrees. For example, at the time $t=30000$ minutes, the settlements are approximately $2.67 \mathrm{~mm}, 2.76 \mathrm{~mm}, 2.84 \mathrm{~mm}$, $2.92 \mathrm{~mm}$, and $3.00 \mathrm{~mm}$ if $C_{s}$ is $0.002,0.004,0.006,0.008$, and 0.010 , respectively. Because $C_{s}$ remains constant, the settlements increase linearly in the process of secondary consolidation. 
Overall, the influence $C_{s}$ makes on the calculation results of settlement is evident in the initial stage of primary consolidation and the final stage of secondary consolidation. Hence, the value of $C_{s}$ should be precisely estimated before performing the numerical analysis.

\section{Conclusions}

The nonlinear finite strain consolidation with secondary consolidation behavior was analyzed in this paper. The following conclusions can be made.

(1) Based on some assumptions about the secondary consolidation behavior of soils, Gibson's consolidation theory is modified.

(2) Considering the nonlinear compressibility and nonlinear permeability of soils, the new governing equation for finite strain consolidation analysis is derived.

(3) The excess pore water pressures calculated with different methods are compared. It can be seen that Gibson's method may underestimate the excess pore water pressure in the intermediate and final stages of primary consolidation.

(4) The time-deformation curves calculated with different methods are compared; it can be found that the new method can precisely estimate the settlement rate and the final settlement of Hangzhou soft clay sample.

(5) By considering different new secondary consolidation indices, five time-deformation curves are calculated and compared. It can be found that the influence $C_{s}$ makes on the calculation results of settlement is remarkable in the initial stage of primary consolidation and the final stage of secondary consolidation.

\section{Conflict of Interests}

The authors declare that there is no conflict of interests regarding the publication of this paper.

\section{Acknowledgment}

The financial supports from the National Natural Science Foundation of China under Grant no. 51378469, Zhejiang Provincial Natural Science Foundation of China under Grant no. Y1111240, and the Natural Science Foundation of Ningbo City, China, under Grant no. 2013A610196 are gratefully acknowledged.

\section{References}

[1] C. C. Ladd, R. Foott, K. Ishihara, F. Schlosser, and H. G. Poulus, "Stress-deformation and strength characteristics," in Proceedings of the 9th International Conference on Soil Mechanics and Foundation Engineering, vol. 2, pp. 421-494, Tokyo, Japan, 1977.

[2] M. Jamiolkowski, C. C. Ladd, J. T. Germaine, and R. Lancellotta, "New developments in field and laboratory testing of soils," in Proceedings of the 11th International Conference on Soil
Mechanics and Foundation Engineering, vol. 1, pp. 150-153, San Francisco, Calif, USA, 1985.

[3] G. Mesri and P. M. Godlewski, "Time and stress-compressibility interrelationship," Journal of Geotechnical Engineering, vol. 103, no. 5, pp. 417-430, 1977.

[4] G. Mesri and A. Castro, " $C_{\alpha} / C_{c}$ concept and Ko during secondary compression," Journal of Geotechnical Engineering, vol. 113, no. 3, pp. 230-247, 1987.

[5] G. Mesri, "Primary compression and secondary compression," in Soil Behavior and Soft Ground Construction, vol. 119, pp. 122166, Geotechnical Special Publication, ASCE, 2003.

[6] L. Barden, "Consolidation of clay with non-linear viscosity," Géotechnique, vol. 15, no. 4, pp. 345-362, 1965.

[7] H. E. Wahls, "Analysis of primary and secondary consolidation," Journal of Soil Mechanics and Foundations Division, vol. 88, no. 6, pp. 207-223, 1962.

[8] H. Aboshi, "An experimental investigation on the similitude in the consolidation of a soft clay including the secondary creep settlement," in Proceedings of the 8th International Conference on Soil Mechanics and Foundation Engineering, vol. 4, pp. 8893, Moscowm, Russia, 1973.

[9] S. Leroueil, M. Kabbaj, F. Tavenas, and R. Bouchard, "Stressstrain-strain rate relation for the compressibility of sensitive natural clays," Géotechnique, vol. 35, no. 2, pp. 159-180, 1985.

[10] S. Leroueil, M. Kabbaj, F. Tavenas, and R. Bouchard, "Reply to discussion on stress-strain-strain rate relation for the compressibility of sensitive natural clays," Géotechnique, vol. 36, no. 2, pp. 283-290, 1986.

[11] M. Kabbaj, F. Tavenas, and S. Leroueil, "In situ and laboratory stress-strain relationships," Géotechnique, vol. 38, no. 1, pp. 83100, 1988.

[12] R. E. Gibson, G. L. England, and M. J. L. Hussey, "The theory of one dimensional consolidation of saturated clays, I. Finite nonlinear consolidation of thin homogeneous layers," Géotechnique, vol. 17, no. 3, pp. 261-273, 1967.

[13] R. E. Gibson, R. L. Schiffman, and K. W. Cargill, "The theory of one-dimensional consolidation of saturated clays. II. Finite nonlinear consolidation of thick homogeneous layers," Canadian Geotechnical Journal, vol. 18, no. 2, pp. 280-293, 1981.

[14] X.-Y. Xie, J.-F. Zhang, and G.-X. Zeng, "Similarity solution of self-weight consolidation problem for saturated soil," Applied Mathematics and Mechanics, vol. 26, no. 9, pp. 1165-1171, 2005.

[15] S. Jeeravipoolvarn, R. J. Chalaturnyk, and J. D. Scott, "Sedimentation-consolidation modeling with an interaction coefficient," Computers and Geotechnics, vol. 36, no. 5, pp. 751-761, 2009.

[16] R. L. Schiffman, "Finite and infinitesimal strain consolidation," Journal of Geotechnical Engineering, vol. 106, pp. 203-207, 1980.

[17] K. W. Cargill, "Prediction of consolidation of very soft soil," Journal of Geotechnical Engineering, vol. 110, no. 6, pp. 775-795, 1984.

[18] S. H. Toh and M. Fahey, "Numerical and centrifuge modelling of large strain consolidation," in Computer Methods and Advances in Geomechanics, pp. 279-284, Balkema, Rotterdam, The Netherlands, 1991.

[19] H. B. Dan, Time dependent behavior of natural soft clays [Ph.D. dissertation], Zhejiang University, Hangzhou, China, 2009, (Chinese).

[20] Y. H. Liu, Study on engineering property and application of constitutive model for ningbo soft clay [Ph. D. dissertation], Zhejiang University, Hangzhou, China, 2008, (Chinese). 
[21] Z.-X. Ding, D.-J. Yuan, and H.-H. Zhu, "A novel coupling model for 1D finite-strain primary-secondary consolidation," Rock and Soil Mechanics, vol. 31, no. 8, pp. 2367-2372, 2010 (Chinese).

[22] J. M. Duncan, "Limitations of conventional analysis of consolidation settlement," Journal of Geotechnical Engineering, vol. 119, no. 9, pp. 1331-1359, 1993.

[23] S. Leroueil, "Tenth Canadian geotechnical colloquium: recent developments in consolidation of natural clays," Canadian Geotechnical Journal, vol. 25, no. 1, pp. 85-107, 1988.

[24] G. Mesri and A. Rokhsar, "Theory of consolidation for clays," Journal of Geotechnical and Geoenvironmental Engineering, vol. 100, no. 8, pp. 889-904, 1974.

[25] F. Tavenas, P. Jean, P. Leblond, and S. Leroueil, "The permeability of natural soft clays. Part II: permeability characteristics," Canadian Geotechnical Journal, vol. 20, no. 4, pp. 645-660, 1983.

[26] A.-F. Hu, J.-Q. Huang, X.-Y. Xie, J. Wu, J.-Z. Li, and K.-F. Liu, "Study on properties of one-dimensional complex nonlinear consolidation considering self-weight of saturated soils," Journal of Zhejiang University: Engineering Science, vol. 46, no. 3, pp. 441-447, 2012 (Chinese).

[27] Y. Ichikawa, K. Kawamura, N. Theramast, and K. Kitayama, "Secondary and tertial consolidation of bentonite clay: consolidation test, molecular dynamics simulation and multiscale homogenization analysis," Mechanics of Materials, vol. 36, no. 5-6, pp. 487-513, 2004. 


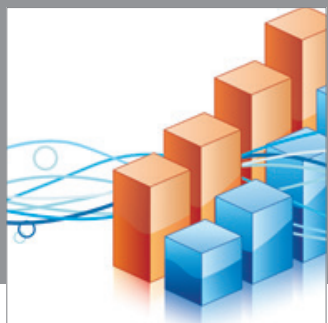

Advances in

Operations Research

mansans

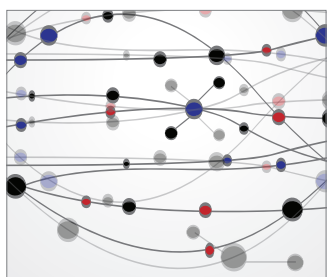

The Scientific World Journal
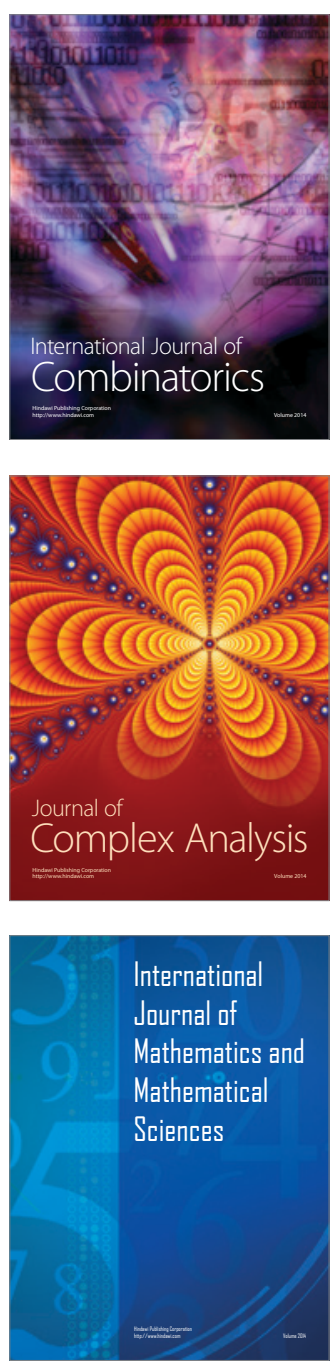
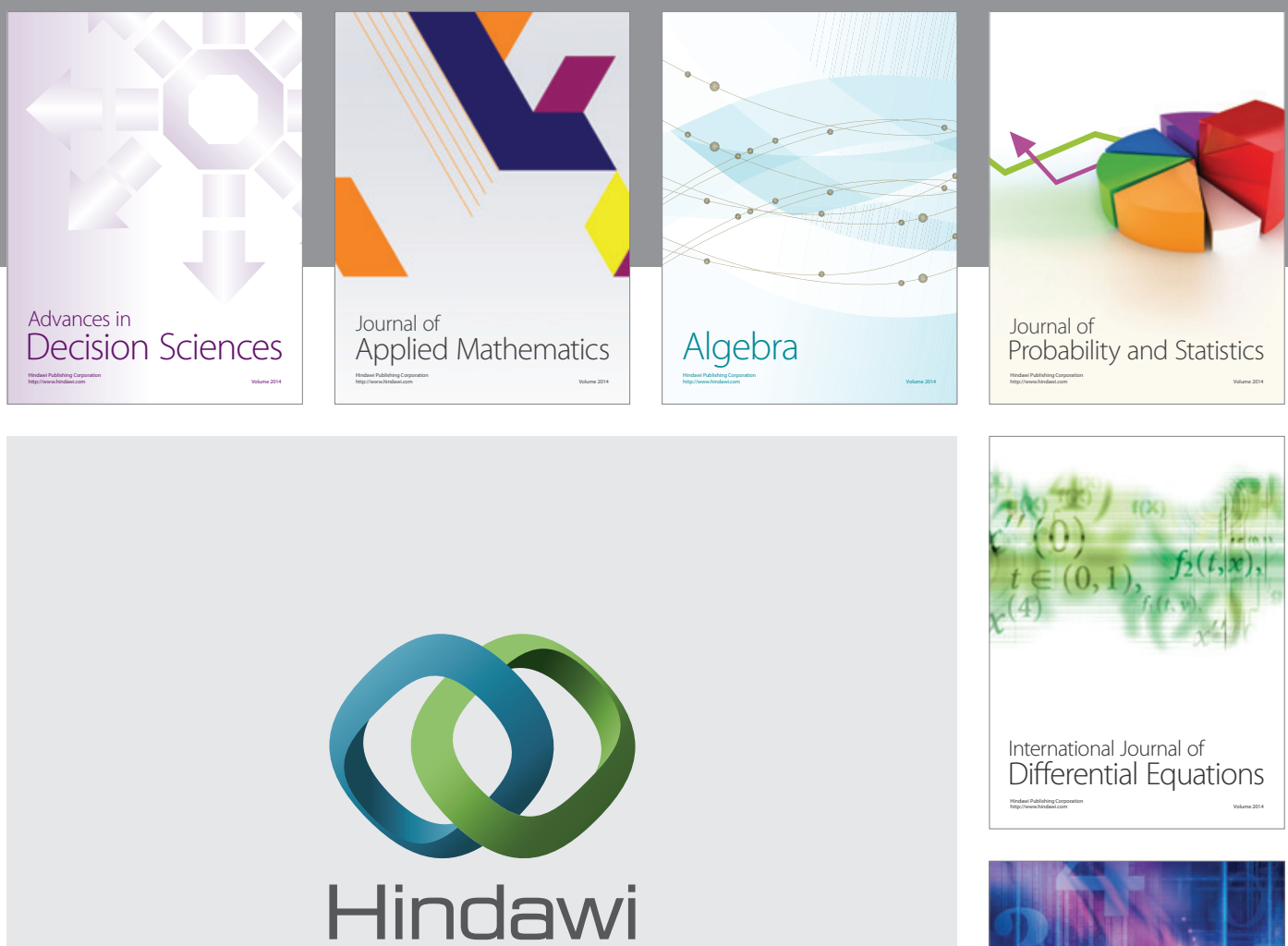

Submit your manuscripts at http://www.hindawi.com
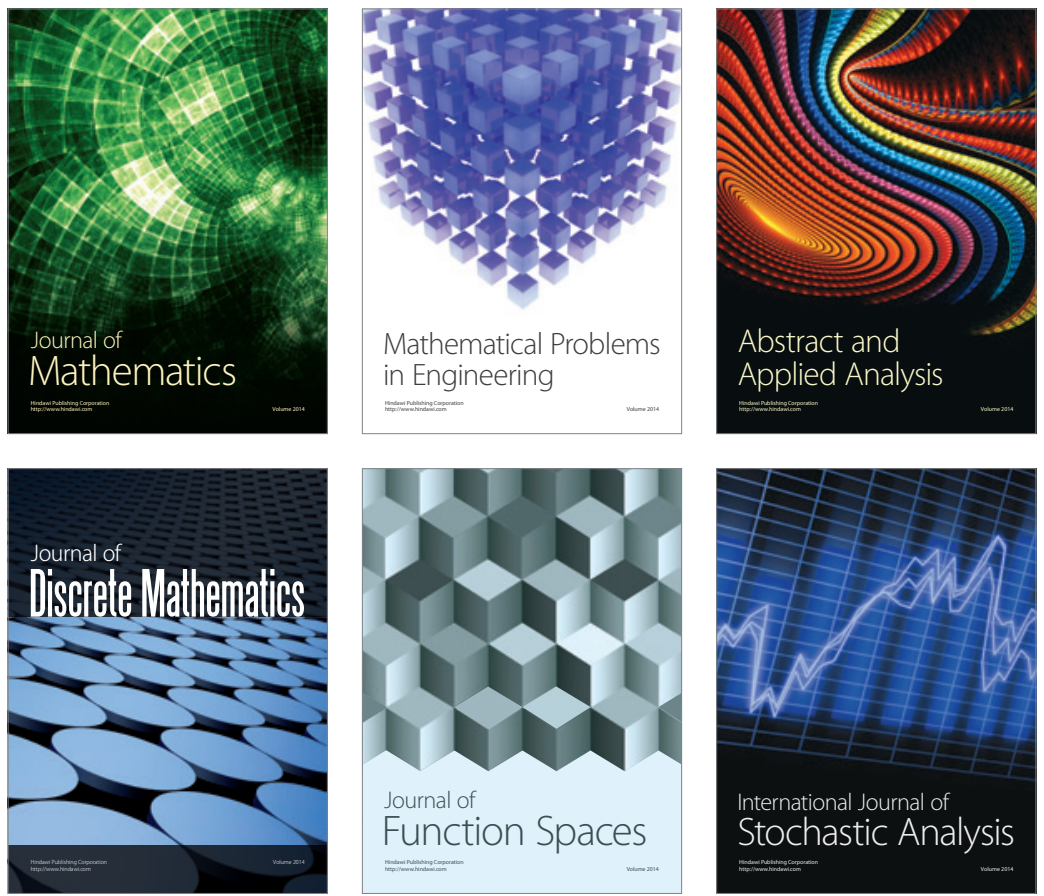

Journal of

Function Spaces

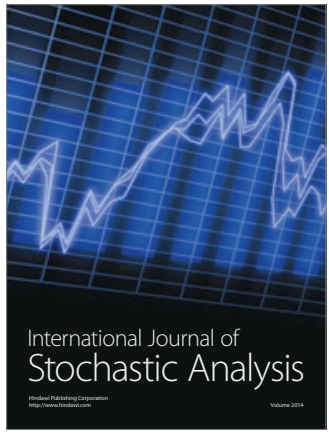

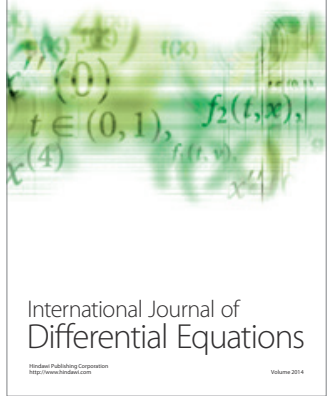
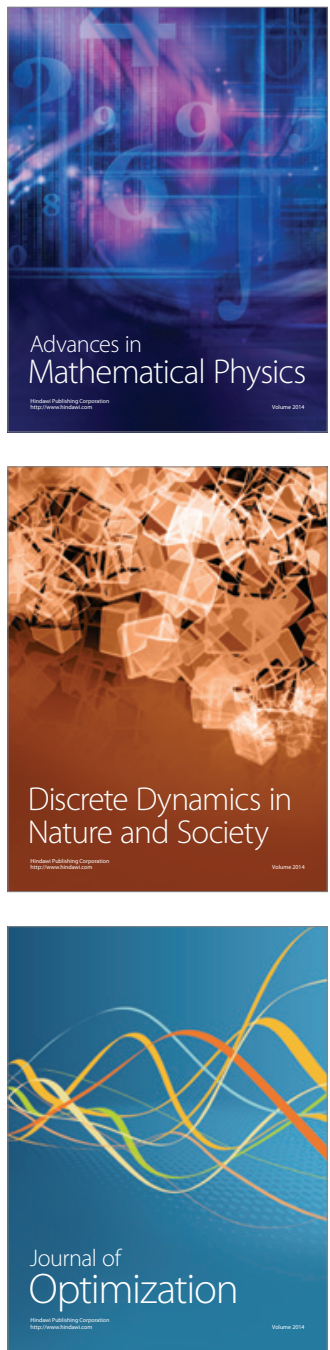